\title{
Location Planning of Fire Service Fleet Based on Forest Fire Susceptibility
}

\author{
STAVROS SAKELLARIOU ${ }^{1,2}$, ATHANASSIOS SFOUGARIS $^{1}$, AND OLGA \\ CHRISTOPOULOU ${ }^{2}$ \\ ${ }^{1}$ Department of Agriculture Crop Production and Rural Environment, University of Thessaly, 38446 \\ Volos, GREECE \\ 2 Department of Planning and Regional Development, University of Thessaly, 38334, Volos, \\ GREECE
}

\begin{abstract}
Forest fires constitute one of the greatest risks for certain ecosystems services. Hence, the location planning of firefighting units based on forest fire hazard is a key point for the immediate containment of fire incidents before they become uncontrollable. The primary aim of the paper is the estimation and finding of the required number and positions (i.e. the exact geographical locations and the respective type of installation - fire hydrant etc.) of fire fleet to fully cover (in terms of travel time) the districts of fire services in Chalkidiki (Greece), taking into account the scalable fire susceptibility. The proposed location plans revealed the fact that most of the regions may adequately respond to the fire vulnerability with the current forces, whereas a few regions clearly need a reinforcement in order to sufficiently cover their territories. A future perspective may be related with the exploration of best locations through the entire study area, merging the current administrative boundaries. One more asset of the project constitutes the flexibility and applicability of the sub-modules to other geographic regions after the necessary adjustments to local conditions.
\end{abstract}

Key-Words: - forest fires; fire susceptibility; location planning; Chalkidiki, Greece Received: April 13, 2020. Revised: August 28, 2020. Accepted: September 14, 2020. Published: September 18, 2020.

\section{Introduction}

Forest fires constitute one of the greatest risks for certain ecosystems services that are related with the forest sector (forest timber; climate change regulation etc.) [1]. The complexity of forest fires phenomenon may be related with the interaction of predictability of such phenomena and the expected losses as well as with the impact of the adopted fire management activities [2]. Hence, the location planning of firefighting units based on forest fire hazard is a key point for the immediate containment of fire incidents before they become uncontrollable.

The estimation of forest fire hazard is a crucial step, so that we can recognize the most vulnerable regions. Many researchers have proceeded to the exploration of key factors (e.g. vegetation, climatic, topographic and human-originated factors) that lead to increased fire hazard [3-6] as well as to the fire ignition detection [7-8].

The operational perspective is related with the immediate reaction of fire service through the minimization of travel time to reach any forest fire event. To this end, Dijkstra algorithm [9] has been widely used for the estimation of shortest route between given locations. The location planning for emergencies [10-12] is an issue of utmost importance, since it may prevent destructive events with multiple environmental and social repercussions.

Our paper tries to expand the current state of the literature, calculating the required number and positions (i.e. the exact geographical locations and the respective type of installation - fire hydrant etc.) of fire vehicles in order to reach the most susceptible regions in the least possible time. In the same context, we have computed the needs for each administrative district with distinct operational responsibility, proposing the re-allocation of fire vehicles from fire services with high number of forces to the regions with inadequate number of fire vehicles.

Thus, the objectives of the current analysis are: i) The estimation and finding of the minimum number of optimal locations of fire fleet to fully cover the study area, based on the typical characteristics of the road network (calculation of travel time based on the allowable maximum speed); 2) The determination of possible type of installation (e.g. fire hydrant; water tank, position without any type of installation etc.) for each selected position, where the fire trucks could temporarily park. The outcomes of the above submodules will be based on the assessment of forest fire 
vulnerability. The optimization will take place in the geographical districts of Chalkidiki in which the operational responsibility is distributed among different local fire services.

\section{Materials and Methods}

\subsection{Study area}

The study area is the prefecture of Chalkidiki which is located in the north of Greece. The geographic coordinates of Chalkidiki Perfecture consist of: Geographic latitude $40^{\circ} 20^{\prime} \mathrm{N}$ and Geographic longitude $23^{\circ} 30^{\prime} \mathrm{E}$. It is a coastal area which hosts very flammable material (forests and shrubs). The highest altitude is $1,162 \mathrm{~m}$. [13]. The average temperatures with the highest records occur in July $\left(28,1^{\circ} \mathrm{C}\right)$ and August $\left(27,7^{\circ} \mathrm{C}\right)$. In the same context, the average humidity with the least records have occurred in July $(49,4 \%)$ and August $(52 \%)$. The mean rainfall for July is $23.8 \mathrm{~mm}$ and $16.2 \mathrm{~mm}$. for August. The average wind speed for the same months are 11,9 and $10,8 \mathrm{~km} / \mathrm{h}$ respectively [14]. In a timeframe of the recent 18 years, 5,500 ha of burned area have been recorded, whereas more than $90 \%$ of the above index are forests.

\subsubsection{Materials}

The primary geospatial data that participated in the analysis were: i) the fire agencies establishments and the number of fire fleet for each district [15]; ii) the geographic locations of fire infrastructure [15]; iii) a grid of random points derived from a systematic sampling (covering the entire study area); iv) the boundaries of operational responsibility for each fire agency [16]; v) the road network [17]; and vi) the fire susceptibility map [18]. The Figure 1 depicts the exact position of the study area in national and global perspective, as well as, the distinct zones of operational responsibility of each fire agency.

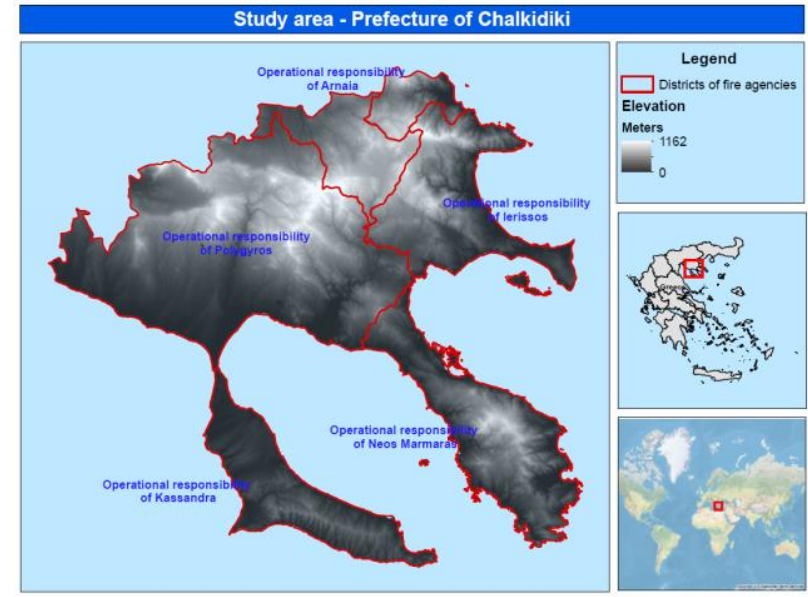

Fig. 1. Study area - Districts of operational responsibility

\section{Methodology}

The foundation of the proposed methodology lies in the maximization of coverage with the least possible facilities, given the scalable degree of fire probability. The fire vulnerability map has been created and refined before the spatial optimization procedures take place [18]. In this paper, the proposed facilities will constitute the locations for the moving fire vehicles. The spatial optimization was conducted into a GIS environment. The core of this process is the development of optimal location plans of fire vehicles, so that these selected positions to primarily be in high proximity to the most vulnerable regions (i.e. high fire probability) within a predefined time threshold [19]. This time threshold should be defined based on the average response time for the study area. Hence, the mean time required by fire vehicles to reach any forest fire event is 27 minutes. At the same time, meeting the above requirement, we tried to minimize the number of these optimal locations [19] in order to save financial resources.

It should be noted that the characteristics of the road network play a decisive role. The inaccessible road segments (footpaths etc.) have been removed from the spatial database. Finally, each road segment has been classified based on their functionality and geometric features (i.e. motorway; service road etc.). Every road category has been assigned an adjusted maximum travel speed respecting the institutional limits [12]. At the last stage, we calculated the travel time of each road segment, since the fire vehicles will be moving through these linear entities. 


\section{Results and Discussion}

This section presents all the locational plans (optimal positions for all the fire vehicles) for each fire agency district with distinct operational responsibility. It should be mentioned that in all these schemes, there is always one fixed location (pre-requirement) which is the permanent fire service headquarters for each district.

The Figure 2 depicts the geographical locations of 7 additional selected positions which cover $99.9 \%$ of the total area of Polygyros district. The minimum number of optimal positions include 4 pre-existing fire hydrants and 3 new random points.

We can see that the fire fleet is dispersed throughout the study area, whereas the fire agency headquarters (in red) is located in the middle of the district.

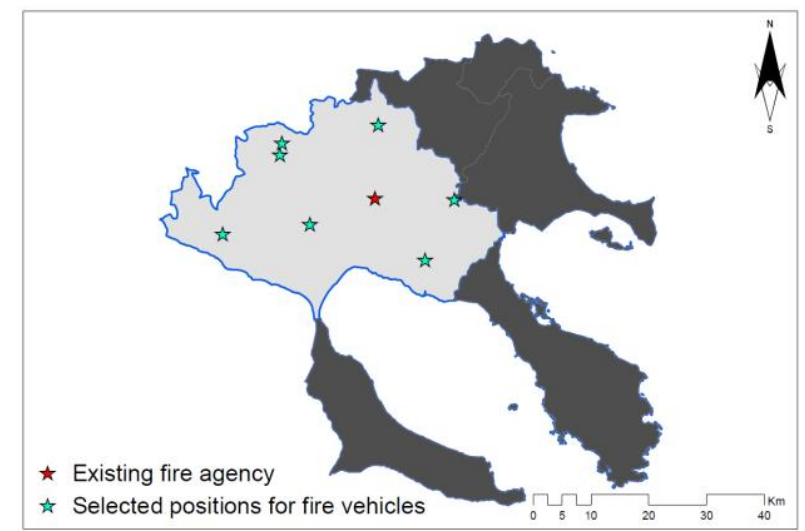

Fig. 2. Selection of minimum number of locations maximizing the coverage of fire susceptibility area in Polygyros district, Chalkidiki

The Figure 3 shows the geographical locations of 2 additional selected locations which cover $100 \%$ of the total area of Kassandra district. The minimum number of optimal positions include 2 points of preexisting fire hydrants.

Here, the area is smaller and the additional 2 locations are primarily located next to forested areas (in the south). There are many agricultural fields in the north of this region, where there is less need for fire vehicles presence.

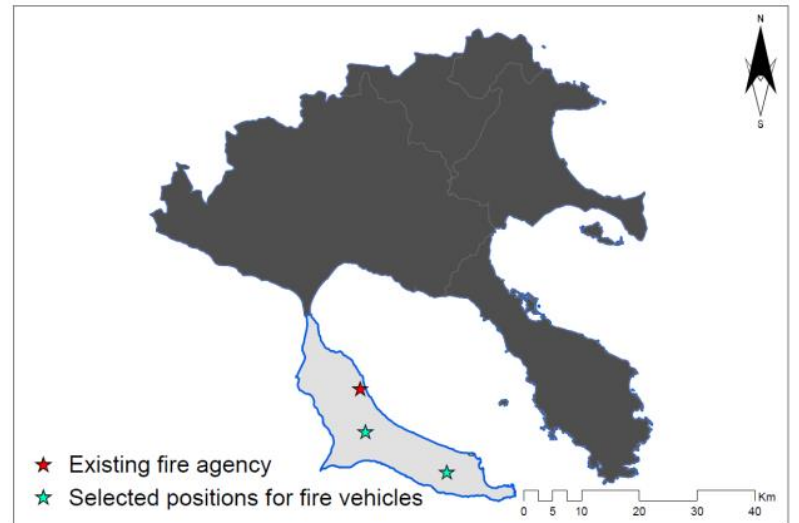

Fig. 3. Selection of minimum number of locations maximizing the coverage of fire susceptibility area in Kassandra district, Chalkidiki

The Figure 4 presents the geographical locations of 3 additional selected locations which cover $100 \%$ of the total area of Neos Marmaras district. The minimum number of optimal positions include 2 preexisting fire hydrants and one patrol position.

Again, the selected positions can be found in the south of this region, where there is one of the most susceptible regions (forests of high flammability etc.)

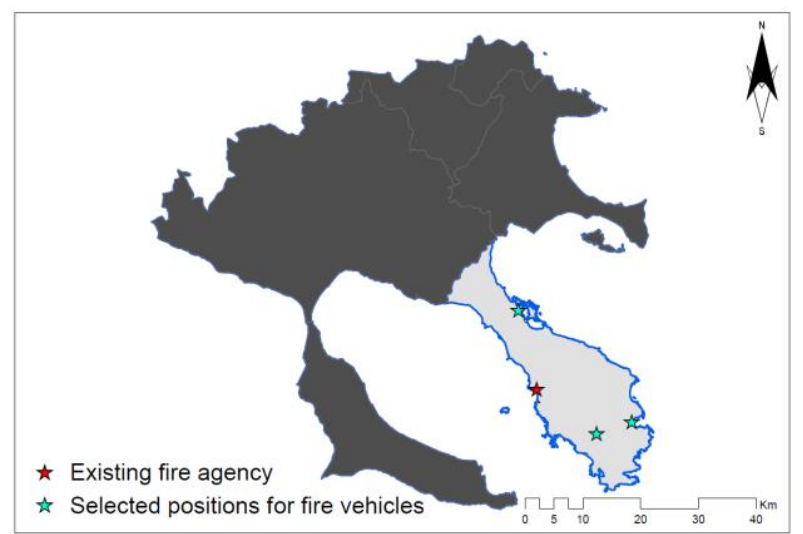

Fig. 4. Selection of minimum number of locations maximizing the coverage of fire susceptibility area in Neos Marmaras district, Chalkidiki

The Figure 5 depicts the geographical locations of 7 additional selected locations which cover $99.3 \%$ of the total area of Ierissos district. The minimum number of optimal positions include 3 pre-existing fire hydrants and 4 random points.

The need for many fire vehicles to be allocated across this region is dictated by the geomorphology of the study area. Here, the terrain is rough, so the travel time can surprisingly be increased (steep slopes). 


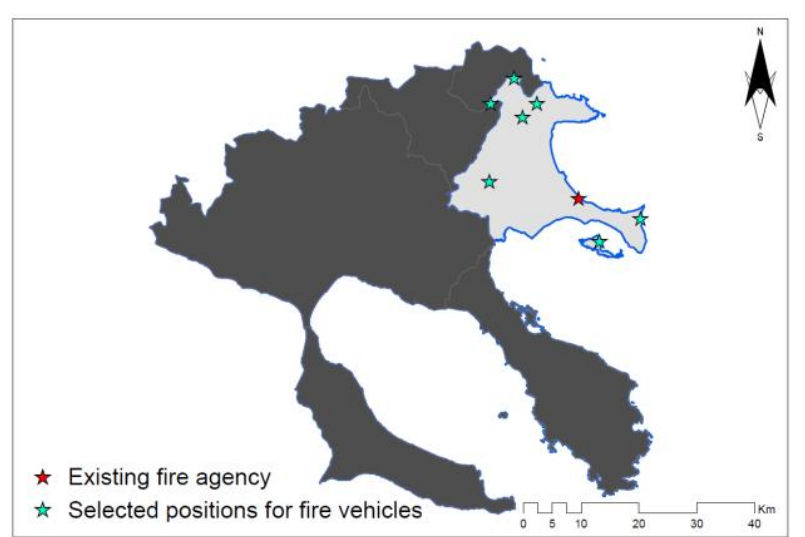

Fig. 5. Selection of minimum number of locations maximizing the coverage of fire susceptibility area in Ierissos district, Chalkidiki

The Figure 6 indicates the geographical locations of 6 additional selected locations which cover $95.8 \%$ of the total area of Arnaia district. The minimum number of optimal positions include 6 random points.

The same remark, as the Ierissos district, applies here. The rough topography and the increased travel time require the demand for much more positions for the fire vehicles.

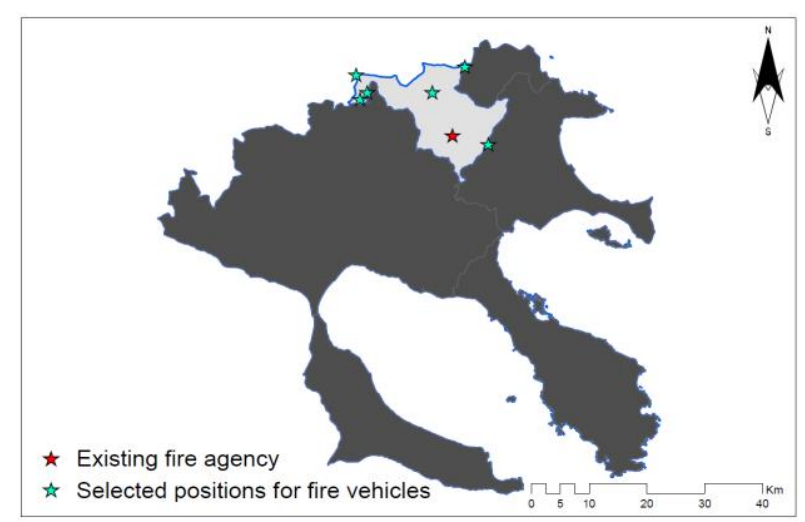

Fig .6. Selection of minimum number of locations maximizing the coverage of fire susceptibility area in Arnaia district, Chalkidiki

The Table 1 summarizes the results of location optimization in relation to the available fire fleet. As we can observe, three over five districts do not need to employ all of their forces. The first column presents the territories of operational responsibility. The second column depicts the required number of optimal locations for the maximization of geographical coverage ( $>95 \%$ ), whereas the second number shows the real number of available fire vehicles. The third column indicates the percentage of coverage when the required number of fire vehicles are employed.

The Polygyros district needs seven over eight available fire vehicles to be allocated properly. This fact indicates that the selected locations of seven fire vehicles would yield to $99.9 \%$ of the geographical coverage of this specific district to be reached in no more than 27 minutes. In addition, there is one vehicle left - available to be exploited for other reasons and/or to reinforce the neighboring districts which face a greater need of fire vehicles in order to sufficiently cover their territory. The Kassandra district only needs two over seven available fire vehicles in order to fully cover its territory of operational responsibility within 27 minutes. In the same context, there are five vehicles left - available to reinforce the adjacent districts. The Neos Marmaras district requires three over four available fire vehicles in order to entirely cover its district within the predefined time limit. The remaining vehicle could stay in the fire agency headquarters for any other reason or to support the neighboring local fire agencies.

On the contrary, there are two over five districts that do need to employ additional forces coming from other administrative units. The Ierissos district needs seven over three available fire vehicles in order to sufficiently cover its territory (i.e. 99.3\%) within the established time threshold. On the other side, the Arnaia district needs six over two fire vehicles, so that it can adequately cover its area of operational responsibility (i.e. $95.8 \%$ ) within the average time of response (i.e. 27 minutes).

Hence there is a disproportion of fire vehicles distribution among the different administrative units. One reason for this is the limited fire history recorded in Arnaia and Ierissos districts, compared to the other districts. However, beyond that, we could have the possibility to employ the remaining seven available fire vehicles from the first three districts (which maximize the coverage of their territory with less fire forces than the available ones) to cover the deficit of eight locations for the last two administrative regions. The proposed allocation is derived if we take the remaining fire vehicles (abstraction of first number from the second one of the second column in the Table 1) and allocate them to the districts which need much more forces (abstraction of second number from the first one of the second column in the Table 1) to maximize the coverage of their territory.

Table 1. Required vs available number of optimal locations and ideal percentage of coverage for each district of operational responsibility 


\begin{tabular}{|c|c|c|}
\hline $\begin{array}{c}\text { Districts of } \\
\text { operational } \\
\text { responsibilit } \\
\mathbf{y}\end{array}$ & $\begin{array}{c}\text { Required } \\
\text { versus available } \\
\text { number of fire } \\
\text { vehicles to meet } \\
\text { maximization } \\
\text { of coverage }\end{array}$ & $\begin{array}{c}\text { Percentage } \\
\text { (\%) of } \\
\text { maximization } \\
\text { of coverage }\end{array}$ \\
\hline Polygyros & $7 / 8$ & 99,9 \\
\hline Kassandra & $2 / 7$ & 100 \\
\hline $\begin{array}{c}\text { Neos } \\
\text { Marmaras }\end{array}$ & $3 / 4$ & 100 \\
\hline Ierissos & $7 / 3$ & 99,3 \\
\hline Arnaia & $6 / 2$ & 95,8 \\
\hline
\end{tabular}

Definitely, it should not be ignored the fact that the districts with the largest number of fire vehicles consist either the administrative capital of the Prefecture (Polygyros district) or the districts which have suffered the most in the past (Kassandra and Neos Marmaras). Beyond the above, the climatological characteristics and the human presence are differentiated among those regions. The districts located in the south are characterized by higher levels of drought compared to the northern regions which are located at higher altitudes. Moreover, the human presence has been quite intense the last decades primarily serving touristic purposes. Consequently, the interaction of climatic conditions and increased human activity inevitably escalates the frequency (more accidents) and severity of forest fire events.

\section{Conclusions}

The current study explored the best locational options of fire vehicles for immediate response of any forest fire event based on three critical factors, namely, the forces of each fire agency which have a distinct area of operational responsibility; the forest fire susceptibility; and the road network characteristics. The results revealed the fact that most of the regions may adequately address the fire phenomenon with the current forces, whereas a few regions clearly need a reinforcement in order to sufficiently cover their territories.

One future perspective may be related with the exploration of best locations through the entire study area, merging the current administrative boundaries. Therefore, the re-allocation of the number of fire vehicles could be feasible, leading the most forces where there is truly great need.

In this context, the applicability of the adopted model is feasible to other geographic regions, after exploring the local features that may contribute to increased forest fire hazard (e.g. climatic, topographic and anthropogenic dimensions) in relation to the current state of road network (travel time) and the capacity (number and type of fire machinery) of the local fire service.

\section{References:}

[1] Michetti, M., \& Pinar, M. (2019), Forest fires across Italian regions and implications for climate change: a panel data analysis, Environmental and Resource Economics, 72(1), 207-246.

[2] Gonzalez-Olabarria, J. R., Reynolds, K. M., Larrañaga, A., Garcia-Gonzalo, J., Busquets, E., \& Pique, M. (2019), Strategic and tactical planning to improve suppression efforts against large forest fires in the Catalonia region of Spain, Forest ecology and management, 432, 612-622.

[3] Sakellariou, S., Tampekis, S., Samara, F., Flannigan, M., Jaeger, D., Christopoulou, O., \& Sfougaris, A. (2019), Determination of fire risk to assist fire management for insular areas: the case of a small Greek island, Journal of Forestry Research, 30(2), 589-601.

[4] Sakellariou, S., Cabral, P., Caetano, M., Pla, F., Painho, M., Christopoulou, O., ... \& Vasilakos, C. (2020), Remotely Sensed Data Fusion for Spatiotemporal Geostatistical Analysis of Forest Fire Hazard, Sensors, 20(17), 5014.

[5] Suryabhagavan, K. V., Alemu, M., \& Balakrishnan, M. (2016), GIS-based multicriteria decision analysis for forest fire susceptibility mapping: a case study in Harenna forest, southwestern Ethiopia, Tropical Ecology, 57(1), 33-43.

[6] Jaiswal, R.K., Mukherjee, S., Raju, K.D., Saxena, R. (2002), Forest fire risk zone mapping from satellite imagery and GIS, International Journal of Applied Earth Observation and Geoinformation, 4, 1-10.

[7] Perminov, V.A., \& Soprunenko, E. (2018), An initiation of forest fires as a result of gas pipeline accidents, International Journal of Circuits, Systems and Signal Processing, 12, 210-214.

[8] Ding, D., \& Zhu, S. (2019), A Method of ForestFire Image Recognition Based on AdaBoost-BP Algorithm, International Journal of Circuits, Systems and Signal Processing, 13, 312-319. 
[9] Dijskra, E. W. (1959), A note on two problems in connection with graphs, Nümerische Matematik, 1.

[10] Kai, N., Yao-ting, Z., \& Yue-peng, M. (2014), Shortest Path Analysis Based on Dijkstra's Algorithm in Emergency Response System, Indonesian Journal of Electrical Engineering and Computer Science, 12(5), 3476-3482.

[11] Khayal, D., Pradhananga, R., Pokharel, S., \& Mutlu, F. (2015), A model for planning locations of temporary distribution facilities for emergency response, Socio-Economic Planning Sciences, 52, 22-30.

[12] Sakellariou, S., Samara, F., Tampekis, S., Sfougaris, A., \& Christopoulou, O. (2020), Development of a Spatial Decision Support System (SDSS) for the active forest-urban fires management through location planning of mobile fire units, Environmental Hazards, 19(2), 131-151.

[13] National Cadastre (2012), Copyright 2012, National Cadastre \& Mapping Agency S. A.

[14] HNMS, (2018). Hellenic National Meteorological Service

[15] F.A. Polygyros, (2019). Fire Agency Headquarters of Polygyros district.

[16] Geodata.gov.gr, (2020). Governmental geospatial portal. Available from: http://geodata.gov.gr/en/ ; Accessible on $15 / 03 / 2020$.

[17] Geobabrik, (2018), Geofabrik GmbH and OpenStreetMap Contributors, 2018. Data for Greece. Available from: https://download.geofabrik.de/europe/greece.ht $\mathrm{ml}$; Accessible on 20/12/2018.

[18] Sakellariou, S., Sfougaris, A., Christopoulou, O., Tampekis, S., \& Samara, F. (2019b). Preliminary results of a forest fire probability project in Chalkidiki, Greece. In Proceedings of 7th International Conference on Environmental Management, Engineering, Planning and Economics (CEMEPE 2019) \& SECOTOX Conference, Mykonos, Greece, May 19-24, 2011; pp. 803-809.

[19] Esri, (2019), Location-allocation analysis. Available from https://desktop.arcgis.com/en/arcmap/latest/ext ensions/network-analyst/locationallocation.htm; Accessible on 19/06/2020

\section{Contribution of individual authors to the creation of a scientific article}

Stavros Sakellariou perceived the concept, designed the methodology, carried out the optimization experiments and wrote the paper.

Athanassios Sfougaris and Olga Christopoulou supervised the research and contributed to the writing of the paper.

\section{Acknowledgements - Sources of funding}

This scientific publication took place within the framework of the project "Grant for Post-Doctoral Research" of the University of Thessaly, which is being implemented in the University of Thessaly and financed by the Stavros Niarchos Foundation.

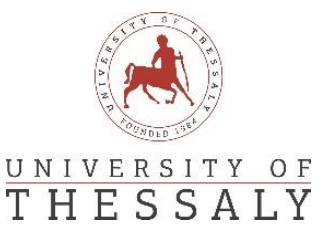

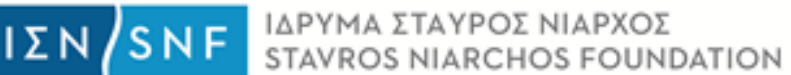

In addition, we would like to thank the three anonymous reviewers for their fruitful comments that led us to the improvement of the paper.

\section{Creative Commons Attribution License 4.0 (Attribution 4.0 International, CC BY 4.0)}

This article is published under the terms of the Creative Commons Attribution License 4.0 https://creativecommons.org/licenses/by/4.0/deed.en_US 